\title{
Very Low Frequency Electromagnetic Induction Surveys in Hydrogeological Investigations; Case Study from Poland
}

\author{
Szymon ORYŃSKI ${ }^{1}$, Marta OKOŃ ${ }^{1}$, and Wojciech KLITYŃSKI ${ }^{2}$ \\ ${ }^{1}$ Institute of Geophysics, Polish Academy of Sciences, Warszawa, Poland; \\ e-mails: sorynski@igf.edu.pl (corresponding author),msliwa@igf.edu.pl \\ ${ }^{2}$ AGH University of Science and Technology, \\ Faculty of Geology, Geophysics and Environment Protection, Kraków, Poland, \\ e-mails: gpklityn@geol.agh.edu.pl,gpklityn@gmail.com
}

\begin{abstract}
In 2011, a geophysical survey was carried out in the surroundings of the Jagiellonian University in Cracow, using a Very Low Frequency method. The measurements were designed to determine the reason of frequent flooding of the lowest level of the building. The main objective of the study was to find out from where and in which way the rainwater seeps into the building and how this problem can be solved in the least invasive manner. The aim of geophysical methods was also to provide necessary information that will enable the construction of a hydrogeological model of the local environment. The interpretation revealed the presence of a sandy gutter surrounded by impermeable clay. There is a big resistivity contrast between those layers. Their location and approximate dimensions were determined.
\end{abstract}

Key words: Very Low Frequency method, groundwater research, electromagnetism, shallow geophysics, near surface. 


\section{INTRODUCTION}

The aim of this study is to examine the extent to which the Very Low Frequency method can be useful in mapping shallowly buried geological structures. VLF EM induction method is used to determine the electric properties of the rock in the superficial zone. Then, on this basis, there is a possibility to establish the type of material present in the examined environment. The method is used in two modes: VLF-R (electric) and VLF (magnetic). A qualitative interpretation method was used to interpret VLF EM data to identify anomalous zones. Research has been done using the VLF-3 Scintrex instrument. The receiving frequency has been set at $21.75 \mathrm{kHz}$ (HWU, Table 1). We have analysed a case which theoretically is on the border of applicability of the method. We tried to detect shallowly buried, watered sand trough in a low resistivity environment. The justification of application VLF method in this case is very simple. There is a big resistivity contrast between layers occurring there (Kleczkowski et al. 1994). Clays and loams have very low electrical resistivity (Table 2), but sands (even saturated by water) are characterized by higher resistivity (Table 3 ). The resistivities of different rocks vary within wide limits. The saline water, which saturates rocks, clays and sands is characterized by ionic conduction, and their resistivities are relatively low (Antoniuk et al. 2003). The increase of the water salinity causes a significant increase in its conductivity (Plewa and Plewa 1992). The main impact on the resistivity of biphasic rock has the component of lower resistivity. In this case, VLF EM as a geophysical method should provide information about the hydrogeological conditions for technical and construction purposes.

\section{VERY LOW FREQUENCY METHOD}

The VLF EM method belongs to the electromagnetic methods applied in near-surface geophysics. Its main application is the mapping of vertical discontinuities such as faults, flexures and ore mineralization zones (Saydam 1981). It is used also in hydrogeological studies and detecting deposits of particular rock material (Chandra 2015).

The VLF method uses electromagnetic waves of very low frequency in terms of radio waves. From the standpoint of geoelectrical methods, these frequencies are considered to be quite high. The sources of such waves are strong military radio stations used to maintain communication with submarines. There are 11 major VLF transmitters distributed around the world (Reynolds 2011). They are emitting waves in the frequency range from 15 to $30 \mathrm{kHz}$. Electromagnetic field is polarized cylindrically around the antenna. Registered electromagnetic waves can be divided into: 
- Ionospheric waves, which once or multiply bounce off the ionosphere and the surface of the earth. The most common are singly (first sky hop) and doubly (second sky hop) reflected waves;

- Spatial waves, which propagate in the air, directly from the transmitter to the receiver;

Ground waves, which propagate in the soil. These are recorded only at short distance from the source.

Source signal is described by cylindrical coordinates, but it is better to transform it into Cartesian system. The primary field contains a vertical electric field component $\left(E_{z}\right)$ and a horizontal (tangent) magnetic field component $\left(H_{y}\right)$, both perpendicular to the direction of propagation, $x$, and a horizontal (radial) electric field component $\left(E_{x}\right)$. Electromagnetic field properties usually are discussed for two areas: the near zone (induction) and far zone (radiation). The far zone refers to the regions in which the distance between transmitter and receiver is many times bigger than the wavelength. The VLF measurements are carried out at a great distance (far zone). Conductors in the earth modify the $H_{y}$ component and create the vertical component $H_{z}$. The vertical magnetic component is measured as ratio $H_{z} / H_{y}$. The primary $H_{y}$ penetrates into the ground and induces eddy currents forming a secondary horizontal electric component in buried conductive structures. At a great distance, the horizontal electric component is much less than the vertical electric component (Tabbagh et al. 1991). A secondary magnetic field is generated which is out of phase with the primary magnetic field. The intensity of the secondary magnetic field depends on the conductivity of the ground (Khalil and Santos 2010). Resultant magnetic field, which is produced by the interference between the primary and the secondary magnetic fields, is elliptically polarized. The parameters of interest are: (a) the orientation of the minor ellipse axis (tilt angle, $\alpha$ ), also called the real (in-phase); and (b) the ratio of the minor to the major ellipse axes of the polarization (ellipticity, e), also called the imaginary (quadrature) component (Karous and Hjelt 1977).

As a result of low attenuation and high diffraction, at a small distance from the source, very long waves propagate mainly as spatial waves. However, at a distance of 1000-2000 km from the transmitter, ionospheric wave field strength exceeds the field strength of spatial waves. These bounce off the lowest layers of the ionosphere, which have very low electron density. Propagation range of these waves is very large and extends over several thousand kilometres (McNeill and Labson 1992).

The most powerful transmitters emitting frequencies of interest to us are summarized in Fig. 1. The ellipses mark the ranges of spatial waves. Ionospheric waves are recorded worldwide. Military stations usually do not 


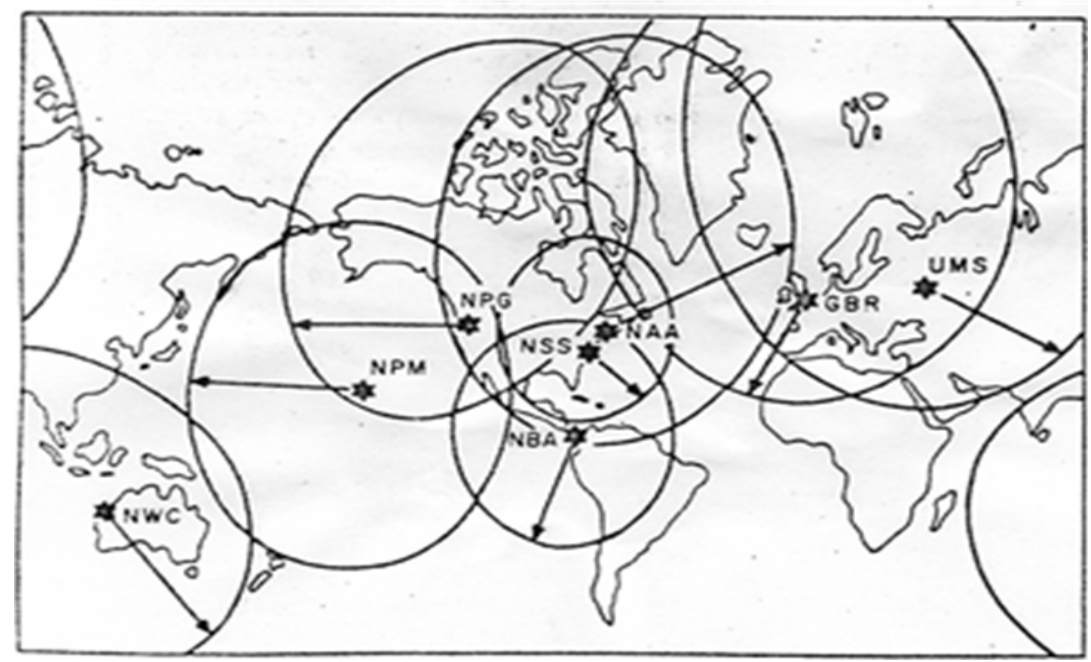

Fig. 1. Location of stations; ellipses mark the maximum range of spatial waves, source: Scintrex (1988).

provide a continuous signal. Station designated as HWU transmits practically without significant breaks. It is the Rosnay station in France, which emits electromagnetic waves with a frequency of $21.75 \mathrm{kHz}$ (HWU France). A list of the transmitters whose signals are received in Poland is presented in Table 1 (Graf et al. 2011).

Table 1

List of VLF transmitters whose signals are received in Poland (source: http://www.classaxe.com/dx/ndb/reu/)

\begin{tabular}{|l|c|l|}
\hline ID & Frequency $[\mathrm{kHz}]$ & \multicolumn{1}{|c|}{ Location } \\
\hline VTX & $16.3 ; 17.0$ & India \\
JXN & 16.4 & Norway \\
SAQ & 17.2 & Sweden \\
RDL & $18.1 ; 21.1$ & Russia \\
HWU & $18.3 ; 21.75 ; 22.6$ & France \\
NWC & 19.8 & Australia \\
ICV & 20.27 & Italy \\
NPM & 21.4 & USA \\
GQD & 22.1 & United Kingdom \\
DHO38 & 23.4 & Germany \\
NAA & 24.0 & USA \\
NML4 & 25.4 & USA \\
TBB & 26.7 & Turkey \\
\hline
\end{tabular}




\section{METHODOLOGY AND DATA ACQUISITION}

The method is based on measurement of the secondary fields produced by the underground conductive bodies, which are subject to action of the primary electromagnetic field. Although the source of the waves is artificial, we classify the VLF method as passive and operating in a far field of the source. The reason is that the signal transmission is done completely independently of its registration (serves other purposes), and takes place at a distance of at least several hundred kilometres from the research area. We can therefore consider an electromagnetic wave as a planar rather than spherical wave. In the VLF method, measurements are carried out mostly along profiles parallel to each other. Theoretically, designing profiles perpendicular to the investigated structure should lead to the best results. However, the course of the structures seldom is well understood, which requires previous reconnaissance measurements (Kaufman and Keller 1981).

The sensors do measurement the total field consisting of the primary and secondary field. Like the primary field, secondary field contains also two horizontal components, vibrating perpendicular to the direction of wave propagation. Also, the vertical component is measured. As a result of measurements, we obtain three components: $E_{x}, H_{y}$, and $H_{z}$. Horizontal components $E_{x}$ and $H_{y}$ are derived from primary and secondary fields, while the component $H_{z}$ comes from the secondary field only. Due to measured components, the measurement can be divided into magnetic mode $\left(H_{z}\right.$ and $H_{y}$ components are measured) and electric mode $\left(E_{x}\right.$ and $\left.H_{y}\right)$. In the VLF method, the apparent resisitivity $\left(\rho_{a}[\Omega \mathrm{m}]\right)$ is obtained by calculating the impedance $\left(Z=E_{x} / H_{y}\right)$ from measured components in electric mode, according to the following formula similar to magnetotelluric measurement (Zdhanov and Keller 1994):

$$
\rho_{a}=\frac{1}{\omega \mu_{0}} \cdot\left|\frac{E_{x}}{H_{y}}\right|^{2},
$$

where $\rho_{a}[\Omega \mathrm{m}]$ is the apparent resistivity; $\omega$ is the angular frequency, which is equal to $2 \pi f$, where $f$ is a frequency of an electromagnetic wave in Hertz; $\mu_{0}$ is the magnetic permeability of a vacuum, which is equal to $4 \pi \cdot 10^{-7}$ [Vs/Am]; and $E_{y}$ and $H_{x}$ are horizontal components of the electric and magnetic field, respectively, expressed in millivolts per meter $[\mathrm{mV} / \mathrm{m}]$ and in microamperes per meter $[\mu \mathrm{A} / \mathrm{m}]$.

The unit of apparent resistivity is the same as for the true resistivity $[\Omega \mathrm{m}]$, but only for a homogeneous medium these parameters are equal in value. In any other case, we obtain a function reflecting the distribution of resistivity in the ground only approximately (Tabbagh et al. 1991). At the 
beginning, the analysis of apparent resistivity along individual profiles is done. Interpolated data from several profiles allow obtaining an estimated apparent resistivity distribution in the study area. The second parameter obtained in the electric mode is the phase shift of impedance, expressed in degrees (Zhdanov and Keller 1994).

$$
\varphi=\tan ^{-1}\left[\frac{\operatorname{Im} \frac{E_{x}}{H_{y}}}{\operatorname{Re} \frac{E_{x}}{H_{y}}}\right] .
$$

For a homogeneous half-space, the phase shift of impedance should be equal to -45 degrees or 45 degrees. The sign depends on the approach used for the solution of Helmholtz equation. The instrument which was used in this measurement calculates it with the negative sign. This parameter behaves inversely to the resistivity changes. The phase is maximum, where the apparent resistivity has its maximal slope. It increases when the resistivity of the soil decreases. Primary field coupled with conductors will be substantially shifted in phase. In the magnetic mode, searching for a buried conductor is performed by analyzing the axis of the elongated conductive structure. In a typical application of the VLF method, the conductive structure would reveal as a change in a sign of the vertical component. This characteristic sign reversal is generally analyzed separately for each profile. However, the placement of the component $H_{z}$ on the research area map enables to specify the zone of occurrence of anomalous structures approximately. When the anomalous structure is present, an extreme of the curve for the horizontal component $\left(H_{y}\right)$ can be expected. Above the high-conductivity layer the maximum is received. A low-conductivity layer causes a minimum (Karous and Hjelt 1983).

In the ground, the magnetic field is disturbed in phase and direction. It is attenuated, and the depth range is determined by skin effect. The depth of electromagnetic field penetration is the depth at which the wave amplitude decreases by one neper, in relation to the field at the surface of the earth. Depth range can be estimated using the following formula (Spies 1989):

$$
\delta=503.3 \cdot \sqrt{\rho / f} .
$$

As is clear from the formula, the depth range depends only on the average resistivity and frequency. Considering that it is based here on a fixed frequency wave, the depth range depends only on the average resistivity in the soil. 


\section{DATA ANALYSIS AND INTERPRETATION}

Research area was located near the Faculty of Management and Social Communication of the Jagiellonian University in Cracow (Lesser Poland, Poland). In the picture below (Fig. 2) there are two maps, which present the location of the survey area. Minor map contains location of Cracow city in Poland.

The major map illustrates the research area with greater accuracy. VLF method was used to detect the sand gutters which cause the uncontrolled water flow and flooding of the lowest level of the building. Eight parallel profiles were made in lengths from 43 to $56 \mathrm{~m}$, spaced to each other by $1.5 \mathrm{~m}$. The distance between the measuring points along the profile was $1 \mathrm{~m}$. Rosnay station in France with a transmitted wave frequency of $21.75 \mathrm{kHz}$ served as a source of electromagnetic waves (Bernard and Valla 1991).

Survey area is located on the right bank of Vistula river within Miocene tectonic graben. The graben is filled by clay deposits mainly containing small inserts of evaporates. In the area of interest, the deposits originate from the middle Miocene-Tortonian (Gradziński 1972, Pitera 2004a,b). Tortonian sediments were covered with a thin layer of Holocene alluvial sediments and locally with the Pleistocene weathered deposits. In the area of our survey, shallowly beneath the surface, impervious clay material is divided with small sand structures that let the water through (Pociask-Karteczka 1994). The clay of marine origin, occurring in the area of study, is characterized by a very

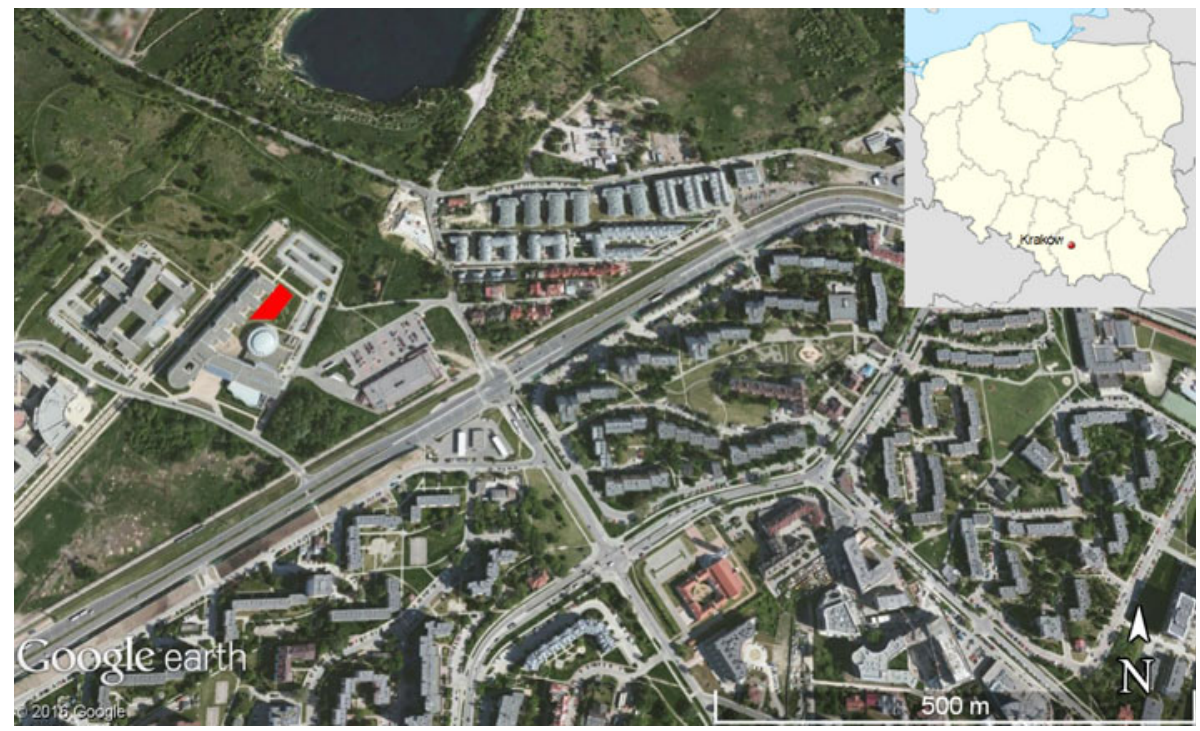

Fig. 2. Location of the survey area. The red polygon stands for study area. Source: Google Earth. 
Table 2

Values of resistivity $(\rho)$ and conductivity $(\sigma)$ of rocks (Kobranova 1989)

\begin{tabular}{|l|c|c|}
\hline \multicolumn{1}{|c|}{ Rock } & $\rho[\mathrm{Wm}]$ & $\sigma[\mathrm{mS} / \mathrm{m}]$ \\
\hline Sand & $100-2500$ & $0.4-10$ \\
Clays & $1-100$ & $10-1000$ \\
Loam & $5-50$ & $20-200$ \\
Marls & $3-70$ & $14-300$ \\
Sandstone & $500-5000$ & $2-20$ \\
Limestone & $1-2 \times 10^{5}$ & $0.5-0.01$ \\
Gypsum & $10^{5}-10^{6}$ & $0.01-0.001$ \\
Anhydrite & $10^{2}-10^{5}$ & $0.001-10$ \\
Rock salt & $10^{4}-10^{8}$ & $10^{-5}-0.1$ \\
\hline
\end{tabular}

Table 3

Values of resistivity $(\rho)$ and conductivity $(\sigma)$ of water (Keller 1966)

\begin{tabular}{|l|c|c|}
\hline \multicolumn{1}{|c|}{ Material } & $\rho[\mathrm{Wm}]$ & $\sigma[\mathrm{mS} / \mathrm{m}]$ \\
\hline Natural waters & $1-100$ & $10-1000$ \\
Saline waters, 3\% & 0.15 (average) & 6700 \\
Saline waters, $20 \%$ & 0.05 (average) & 20000 \\
\hline
\end{tabular}

Table 4

Values of resistivity $(\rho)$ and conductivity $(\sigma)$ of sandstones (Guinea et al. 2010)

\begin{tabular}{|l|c|c|}
\hline \multicolumn{1}{|c|}{ Material } & $\rho[\mathrm{Wm}]$ & $\sigma[\mathrm{mS} / \mathrm{m}]$ \\
\hline Solid sandstone & $>1000$ & $<1$ \\
Saturated sandstone & $<100$ & $<10$ \\
\hline
\end{tabular}

low resistivity (Table 2). In general, the sands have a high resistivity, but rainwater (Table 3) may reduce its value, even to just several ohmmeters (Table 4). So, a slight resistivity contrast should be visible and it would be possible to separate the layers of sandstone from clay.

The depth range of such layers may vary from about 3 to $10 \mathrm{~m}$. The data has been filtered by a $2 \times 2$ window and edited due to disturbances and submitted in the map.

The first analyzed parameter is the distribution of the real magnetic vertical component $\left(H_{z}\right.$ in phase) as ratio $H_{z} / H_{y}$ (Fig. 3). In the behavior of the vertical component the change of sign is of the greatest interest. In the figure a contour line for the value equal to zero $H_{z} / H_{y}$ is marked with a red line. Most of the profiles, between 20 and $30 \mathrm{~m}$, reveal a change of sign in $H_{z} / H_{y}$ 


\section{Distribution of the magnetic component $\mathrm{Hz}$}

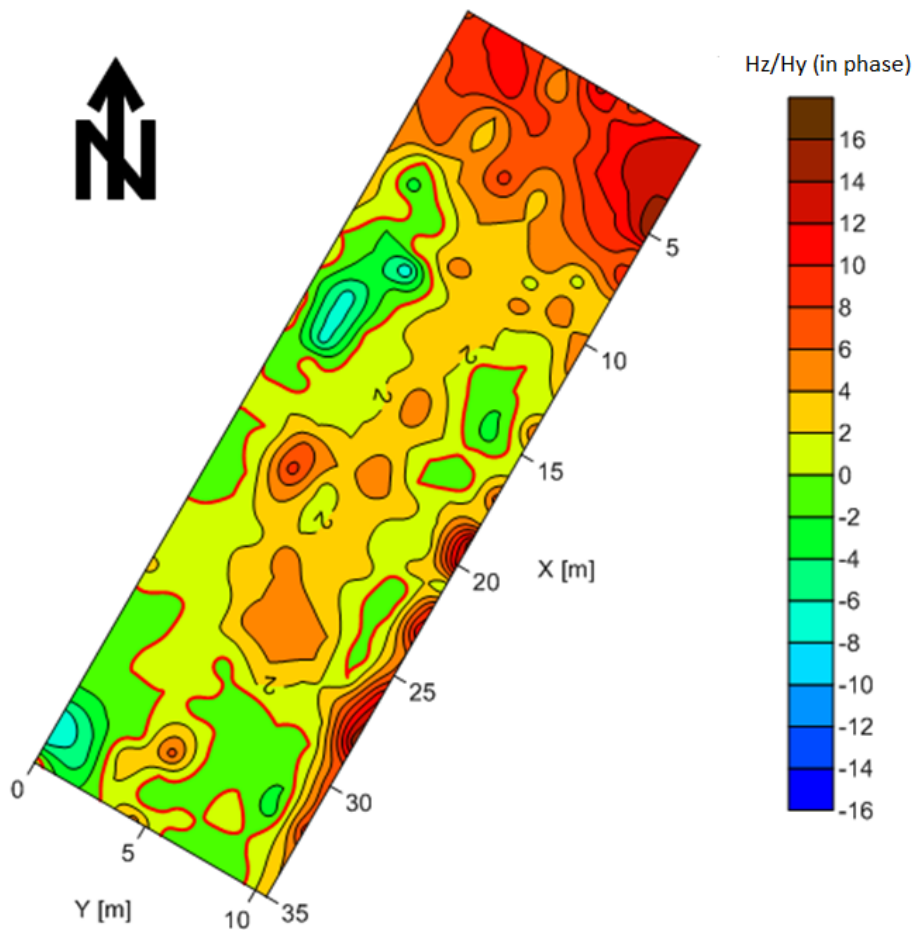

Fig. 3. The distribution of the vertical magnetic field, ratio $H_{z} / H_{y}$ (phase).

value. This zone corresponds to the location of the flooded building. In the northern part of the study area, a very strong positive anomaly shows up in the value of $H_{z} / H_{y}$ in phase. It coincides with a strong minimum of apparent resistivity in this region (Fig. 6).

The distribution of the values of quadrature component $H_{z}$ (quad)/ $H_{y}$ is presented in Fig. 4. We can clearly observe an area in the northern part of the map. This zone is characterized by extremely high positive values of the vertical component, while for the rest of the area the values are negative, reaching their minimum in the southern part of the study area. Extremely low values of the magnetic component in the southern part of the study area may be related to rain-water saturated sands.

For a better illustration of results, they distribution of parameter $H_{z} / H_{y}$ in phase for Profile IV is additionally shown (Fig. 5). This profile is marked by a red line in Fig. 4. The zero crossing around $27 \mathrm{~m}$ of the profile is clearly 


\section{Distribution of the \\ magnetic component $\mathrm{Hz}$}

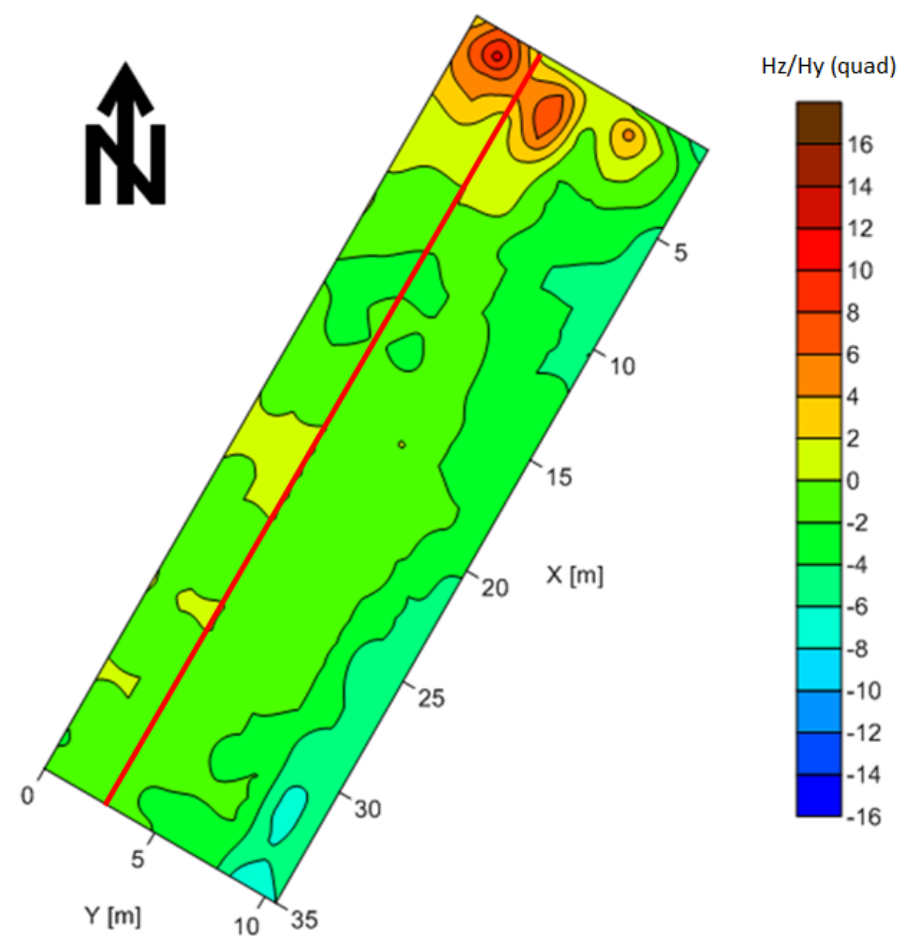

Fig. 4. The distribution of the vertical magnetic field, ratio $H_{z} / H_{y}$ (quadrature). The redline marks Profile IV.

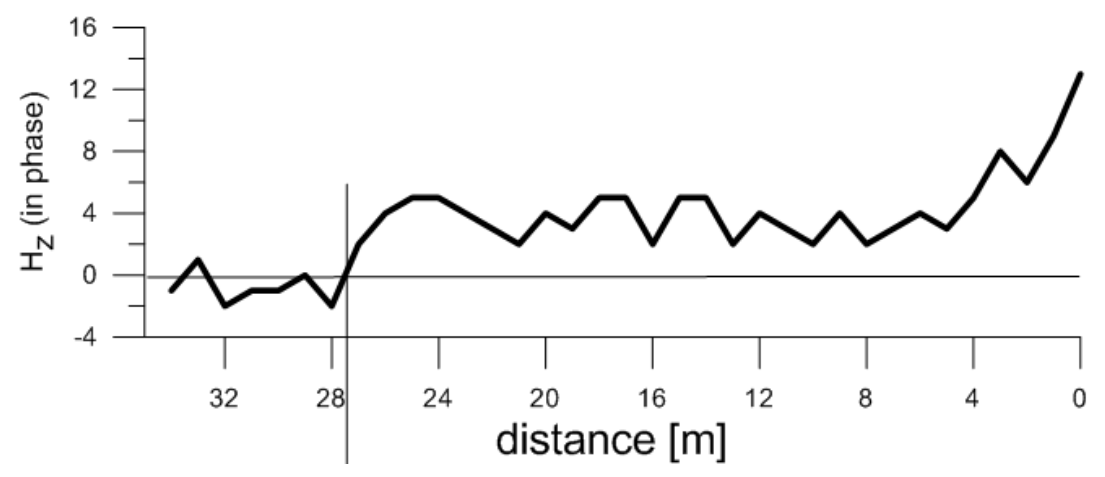

Fig. 5. The distribution of $H_{z}$ in phase component on Profile IV. 


\section{Distribution of the phase shift of impedance}
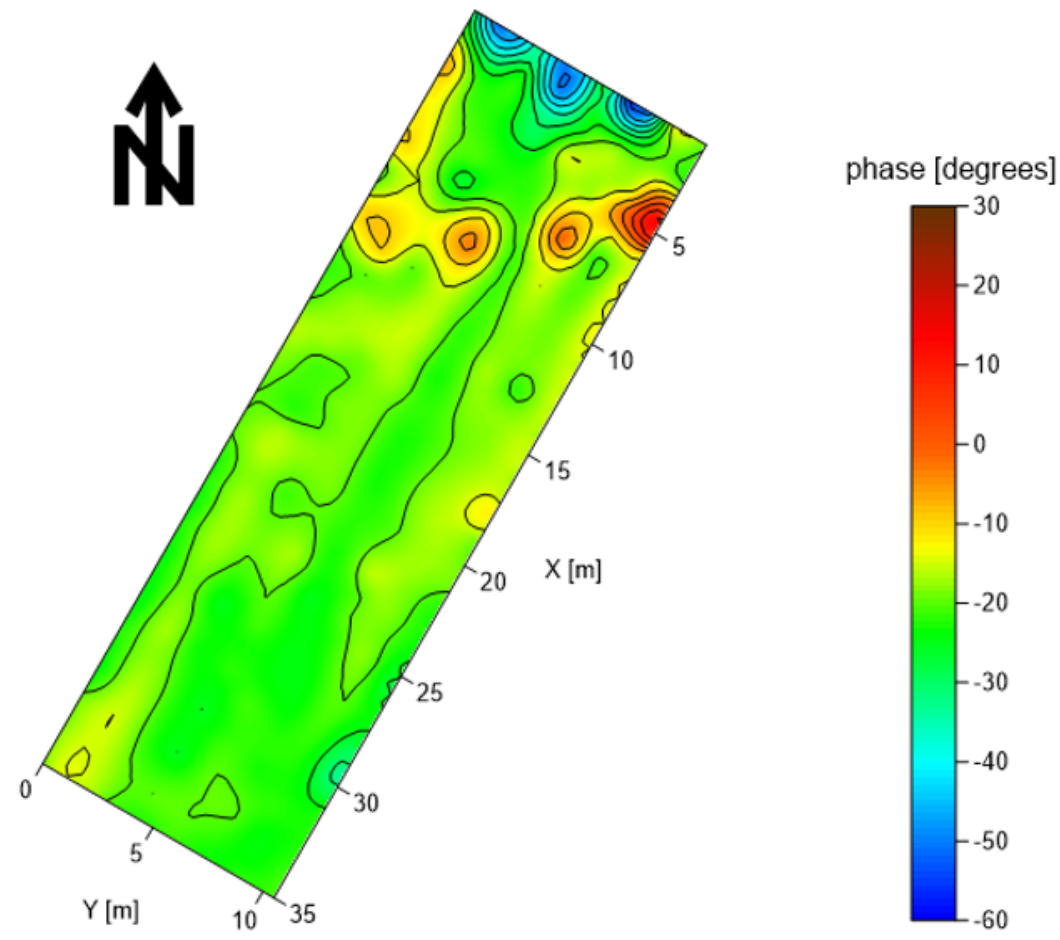

Fig. 6. The distribution of the phase shift of impedance.

visible. This correlates with the location of the gutter. It also coincides with the positive anomaly of the apparent resistivity distribution (Fig. 6).

The next step is to analyze electric parameters as phase shift of impedance and apparent resistivity. Firstly, the distribution of phase shift of impedance is presented (Fig. 6). The instrument used in this measurement calculates this parameter as -45 degrees for homogenous half-space, so it is presented in that way. For the majority of research area the phase shift oscillates about -30 degrees, but in the northern part it grows up to +30 degrees. It is related to accumulation of low resistive clays in there. Phase shift gives better results for good conductors in resistive surroundings, than otherwise. Due to that fact, sandy gutter is not visible in this map.

The last analyzed parameter, which is the most reliable, is the distribution of apparent resistivity (Fig. 7). It is well-known that the vertical component of magnetic field $\left(H_{z}\right)$ well appears in horizontal conductivity 


\section{Distribution of the apparent resistivity}

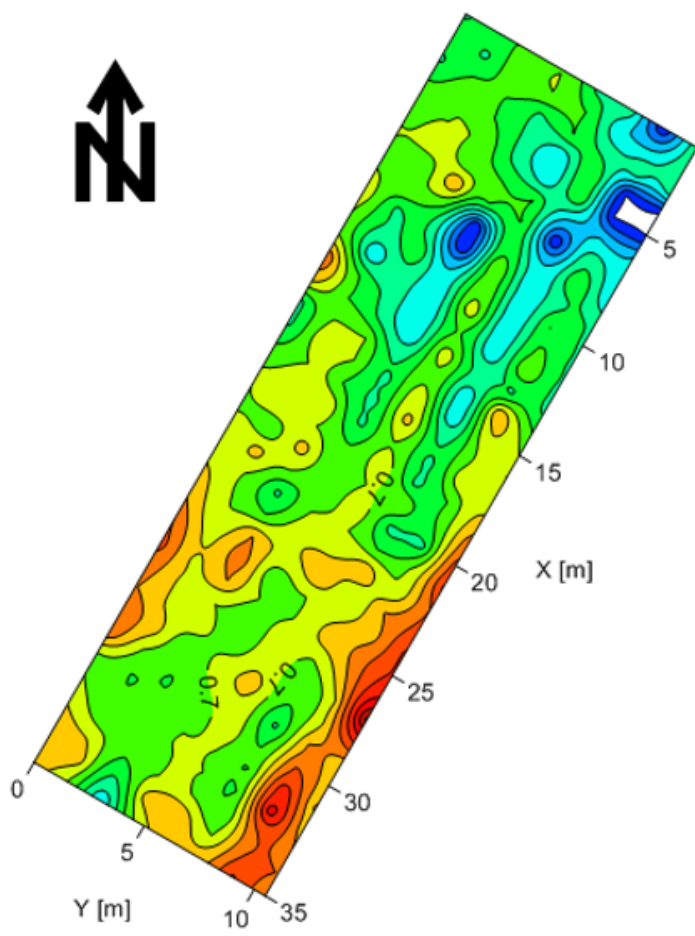

$\log \rho_{\mathrm{a}}[\Omega \mathrm{m}]$

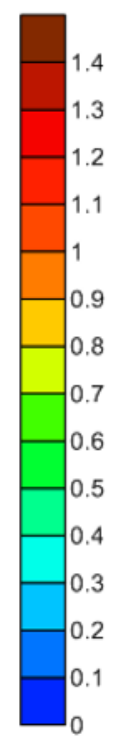

Fig. 7. The distribution of apparent resistivity in a logarithmic scale.

discontinuity, whose strike is not parallel to the direction of propagation of the EM field. In such a situation $H_{z}$ crosses zero value over conductive body (Saydam 1981). In the discussed area, the sand gutter is low-conductive but the other rock, that is, clay is a good conductor. Clays form a lot of conducting bodies, which probably disturbs the magnetic field $\left(H_{z}\right)$. In this discontinuity (sand-clay), the electric field must be of interest. The electric field $\left(E_{x}\right)$ reacts for local horizontal changes of resistivity because it describes currents flowing across the discontinuity. So the apparent resistivity is probably the most reliable parameter in the area.

The map was made for the logarithm of apparent resistivity due to the high variability of this parameter. The zone of reduced resistivity is clearly visible. It coincides very well with the anomalies of magnetic component $H_{z} / H_{y}$ which were described earlier. In the northern part of the map, a region of extremely low resistivity occurs. The reason for that is the presence of the 

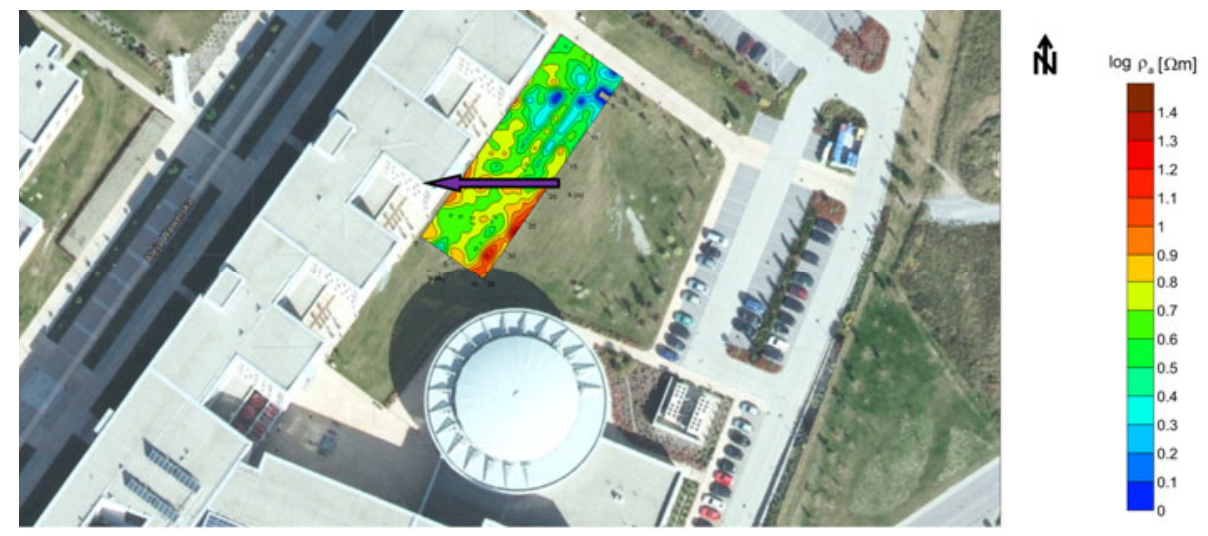

Fig. 8. Distribution of apparent resistivity in a logarithmic scale superimposed on a map of the study area. Purple arrow shows the direction of flooding. Source: www.googlemaps.com.

very low-resistivity clays, which have been described previously. In the central part of the study area, between 20 and $25 \mathrm{~m}$ of profile, there is a zone of increased apparent resistivity. It may indicate the presence of a sandy trough, which is responsible for the flooding of the building.

The last figure (Fig. 8) shows the distribution of apparent resistivity superimposed on a map of the study area.With such a result, we can conclude that just in this area a watered sandy trough is located, with an east-west course, responsible for the flooding of the lowest floor of the building.

\section{DISCUSSION}

These VLF surveys were carried out in order to define the location of a sand gutter. As we can see from the obtained data, our subject has been detected, although with low precision. All analysed parameters revealed an anomaly in the middle part of the study area. It coincides with the expected location of the gutter. The results of the study were affected by an adverse impact of the close proximity to the buildings. It could greatly weaken or distort the signal. This is undoubtedly a disadvantage of VLF method. In these circumstances, the Electrical Resistivity Tomography (ERT) could be very helpful as a complementary method. Both methods seem to be suitable for this particular case from a theoretical point of view. However, taking into account close proximity to the buildings, VLF method is more convenient because it does not require such spacing as the ERT method. 


\section{CONCLUSIONS}

The study shows that although the method is dedicated to the detection of conductors in low-conductive soils, it is also effective for shallow issues detection in low resistivity layers. Small resistivity contrasts between low resistivity materials are very well recorded. Very important matter in this method is to determine the expected depth range. The method is based on a wave with a fixed frequency, so the depth of penetration depends only on the distribution of resistivity in the study area. The higher it is, the greater the range of penetration. The theoretical maximal depth range of the method in this case was calculated as $10 \mathrm{~m}$. For this research the studied structure is located at a depth about $5 \mathrm{~m}$ below the ground. We can conclude that registered anomaly comes from the searched structure. In this case, the theoretical depth of penetration is from 3 to $10 \mathrm{~m}$. Therefore, we can conclude that the recorded anomaly derived from the studied structure. VLF method appears to be sensitive to changes in resistivity, even in low-resistivity rocks. It can be successfully used for the determination of water flow zones. This method is suitable for solving problems related to the protection of buildings against flooding.

\section{References}

Antoniuk, J., W.J. Mościcki, and K. Janicki (2003), Geoelectric investigations of migration of chemically-polluted waters from the post-flotation settlement reservoir “Żelazny Most”, IGSMiE PAN, Kraków, 383-391.

Bernard, J., and P. Valla (1991), Groundwater exploration in fissured media with electrical and VLF method, Geoexploration 27, 1-2, 81-91, DOI: 10.1016/ 0016-7142(91)90016-6.

Chandra, P.C. (2015), Groundwater Geophysics in Hard Rock, CRC Press, 384 pp.

Gradziński, R. (1972), Przewodnik geologiczny po okolicach Krakowa, Wydawnictwa Geologiczne, Warszawa (in Polish).

Graf, K.L., U.S. Inan, and M. Spasojevic (2011), Transmitter-induced modulation of subionospheric VLF signals: Ionospheric heating rather than electron precipitation, J. Geophys. Res. 116, A12, A12313, DOI: 10.1029/ 2011JA016996.

Guinea, A., E. Playa, L. Riverso, M. Nimi, and R. Bosch (2010), Geoelectrical classification of Gypsum Rocks, Surv. Geophys. 31, 6, 557-580, DOI: 10.1007/ s10712-010-9107-x.

Karous, M., and S.E. Hjelt (1977), Determination of apparent current density from VLF measurements. Contribution N. 89, Department of Geophysics, University of Oulu. Finland. 
Karous, M., and S.E. Hjelt (1983), Linear filtering of VLF dip-angle measurements, Geophys. Prospect 31, 5, 782-794, DOI: 10.1111/j.1365-2478.1983. tb01085.x.

Kaufman, A.A., and G.V. Keller (1981), The Magnetotelluric Sounding Method, Elsevier, Amsterdam.

Keller, G.V. (1966), Electrical properties of rocks and minerale. In: S.P. Clark (ed.), Handbook of Physical Constants, The Geological Society of America, $587 \mathrm{pp}$.

Khalil, M.A., and F.M. Santos (2010), Comparative study between filtering and inversion of VLF-EM profile data, Arab. J. Geosci. 4, 1-2, 309-317, DOI: 10.1007/s12517-010-0168-4.

Kleczkowski, A.S., T. Solecki, J. Myszka, and J. Stopa (1994), Krakowskie artezyjskie zdroje wód pitnych z wapieni jury, WGGiOŚ AGH Kraków, 61 pp. (in Polish).

Kobranova, V.N. (1989), Petrophysics, Spinger Verlag, Berlin, 375 pp.

McNeill, J.D., and V.F. Labson (1992), Geological mapping using VLF radio fields. In: M. Nabighian (ed.), Electromagnetic Methods in Applied Geophysics, Vol. 2, Society of Exploration Geophysicists, Tulsa.

Pitera, H. (2004a), Gipsy okolic Krakowa, Aura 7, 11-13 (in Polish).

Pitera, H. (2004b), Gipsy z osiedla Kliny-Zacisze w Krakowie, Wszechświat 105, 79, 201-203 (in Polish).

Plewa, M., and S. Plewa (1992), Pertofizyka, Wyd. Geol., Kraków (in Polish).

Pociask-Karteczka, J. (1994), Changes of water conditions at the Cracow area, Zesz. Nauk. UJ, MCXLIV Pr. Geogr. 96, 38 pp. (in Polish).

Reynolds, J.M. (2011), An Introduction to Applied and Environmental Geophysics, 2nd ed., John Wiley and Sons, Chichester, 796 pp.

Saydam, A.S. (1981), Very low-frequency electromagnetic interpretation using tilt angle and ellipticity measurements, Geophysics 46, 11, 1594-1605, DOI: $10.1190 / 1.1441166$.

Scintrex (1988), User manual Scintrex VLF-3, Geophysical and geochemical instrumentation and services, Scintrex.

Spies, B.R. (1989), Depth of investigation in electromagnetic sounding methods, Geophysics 54, 7, 872-888, DOI: 10.1190/1.1442716.

Tabbagh, A., Y. Bendritter, P. Andrieux, J.P. Decriaud, and R. Guerin (1991), VLF resistivity mapping and verticalization of the electric field, Geophys. Prospect. 39, 8, 1083-1097, DOI: 10.1111/j.1365-2478.1991.tb00360.x.

Zhdanov, M.S., and G.V. Keller (1994), The Geoelectrical Methods in Geophysical Exploration, Elsevier Science. 